University of South Carolina

Scholar Commons

Spring 2004

\title{
Toward a Better Benchmark: Assessing the Utility of Not-at-Fault Traffic Crash Data in Racial Profiling Research
}

\author{
Geoffrey P. Alpert \\ University of South Carolina - Columbia, geoffa@mailbox.sc.edu \\ Michael R. Smith
}

Roger G. Dunham

Follow this and additional works at: https://scholarcommons.sc.edu/crim_facpub

Part of the Law Commons

\section{Publication Info}

Published in Justice Research and Policy, Volume 6, Issue 1, Spring 2004, pages 43-69.

Alpert, G., Smith, M. and Dunham, R. (2004). Toward a Better Benchmark: Assessing the Utility of Not-atFault Traffic Crash Data in Racial Profiling Research. Justice Research and Policy, 6(1), 43-69. (C) 2004 Justice Research and Statistics Association.

This Article is brought to you by the Criminology and Criminal Justice at Scholar Commons. It has been accepted for inclusion in Faculty Publications by an authorized administrator of Scholar Commons. For more information, please contact digres@mailbox.sc.edu. 


\section{W TOWARD A BETTER BENCHMARK: ASSESSING THE UTILITY OF NOT-AT-FAULT TRAFFIC CRASH DATA IN RACIAL PROFILING RESEARCH}

\author{
Geoffrey P. Alpert \\ Michael R. Smith \\ Department of Criminology \\ and Criminal Justice \\ University of South Carolina
}

\author{
Roger G. Dunham \\ Department of Sociology \\ and Criminology \\ University of Miami
}

\section{Abstract}

As studies on racial profiling and biased policing have begun to proliferate, researchers are debating which benchmark is most appropriate for comparison with police traffic stop data. Existing benchmark populations, which include populations estimated from census figures, licensed drivers, arrestees, reported crime suspects, and observed drivers and traffic violators, all have significant limitations. This article offers a new, alternative benchmark for police traffic stops, a benchmark that has not been previously applied or tested in a racial profiling research setting. The analysis presented compares traffic observation data, gathered at selected, high volume intersections during an ongoing racial profiling study in Miami-Dade County, Florida, to not-at-fault driver demographic data from two-vehicle crashes at those same intersections. Findings indicate that non-responsible drivers in two-vehicle crashes appear to represent a reasonably accurate estimate of the racial composition of drivers on the roadways at selected intersections and within areas of varying racial composition. The implications of this finding for racial profiling research are discussed, and suggested areas for future inquiry are identified. 
As concern over racial profiling by the nation's law enforcement agencies has increased, law enforcement administrators and elected officials have responded with administrative policies and state statutes prohibiting racially biased policing and requiring the collection and analysis of data on stops of citizens, including good measures of race and ethnicity. As a result, social science research on police traffic and pedestrian stops has increased exponentially over the last several years (Parker, MacDonald, Alpert, Smith, \& Piquero, 2004). Along with the proliferation of racial profiling studies, a lively debate is going on over the most appropriate methods for gathering, analyzing, and interpreting stop-related data. Among the topics of debate is the crucial question of benchmarking, or finding an accurate comparison for the stops reported by the police (Engel \& Calnon, 2004). Clearly, gathering race and ethnicity data on individuals stopped by the police is of little value unless those data can be measured against some meaningful comparison population (Fridell, Lunney, Diamond, \& Kubu, 2001; McMahon, Garner, Davis, \& Kraus, 2003; Smith \& Alpert, 2002; Fridell, 2004).

In the past, racial profiling researchers have used a variety of populations as benchmarks against which they compared police traffic stop data. One purpose of such comparisons is to ascertain whether minority drivers were stopped disproportionately to their representation in the chosen benchmark population. Comparison populations used in previous studies include adjusted and unadjusted census figures (California Highway Patrol, 2000; Connecticut Division of Criminal Justice, 2000; Greenwald, 2001; Harris, 1999; Missouri Attorney General's Office, 2000; New York Attorney General's Office, 1999; San Diego Police Department, 2000; San Jose Police Department, 1999; Smith \& Petrocelli, 2001; Washington State Patrol, 2001), licensed drivers (Zingraff et.al., 2000), reported crime suspects (Greenwald, 2001; Thomas, 2002), arrestees (New York Attorney General's Office, 1999), and observed drivers and traffic violators (Lamberth, 1997; Zingraff et. al., 2000), among others. Although some of these benchmarks are clearly better than others (see Smith \& Alpert, 2002, and discussion below), each of them suffers from weaknesses that limit, or in some cases obviate, their usefulness as comparison populations in racial profiling research.

The purpose of this article, then, is to offer a new, alternative benchmark for police traffic stops that promises significant advantages over some of the comparison populations currently in use by researchers. This Driving Population Estimation Measure (DPEM) has not been previously applied or tested in a racial profiling research setting. Before discussing the theoretical and empirical foundations for this new benchmark, we first briefly review the existing research on racial profiling, emphasizing the limitations of the benchmark populations now in use (see Engel \& Calnon, 2004; Fridell, 2004). Next, we review a body of literature from traffic safety engineering that serves as the conceptual basis for the new benchmark. Finally, we present a first empirical test of the DPEM benchmark using data from an ongoing study of racial profiling in $\mathrm{Mi}$ ami-Dade County, Florida. 


\section{Benchmarking Limitations in Racial Profiling Research}

\section{Census Data}

Most racial profiling studies to date have used census data as the benchmark against which police traffic stop data have been compared. Evidence is mounting, however, that the census population of an area under study does not accurately represent the driving population available to be stopped (Smith \& Alpert, 2002). For example, researchers in Britain, theorizing that the pedestrian or driving population may vary from the census population in an area of interest, developed innovative methods for identifying the comparison population of those available to be stopped (Miller, 2000). Home Office researchers mounted video cameras on automobiles and used observers to record the race and ethnicity of persons moving about (either as a pedestrian or as a driver) in five areas located in four cities in England. The researchers confirmed that the population of individuals who frequented an area was substantially different from the census-based residential population. In most cases, the pedestrian and vehicular populations of the areas under study were composed of a greater percentage of minorities than the census indicated.

Likewise, researchers in Sacramento, California, found significant differences in the race of drivers observed at key intersections when compared to the census population of the areas in which the intersections were located (Greenwald, 2001). At some intersections minority drivers, observed as a percentage of total observations, far exceeded their proportions in the corresponding census population. At other intersections the reverse was true and minorities were significantly underrepresented relative to the census. In Denver, less than half of the motorists stopped by police from June 2001 through May 2002 were residents of the City of Denver (Thomas, 2002), suggesting that using city census figures for comparison purposes would have been wildly inaccurate. ${ }^{1}$ Finally, as the data from Table 3 below demonstrate, we also catalogued significant differences between the race of observed drivers at intersections in Miami-Dade County and census figures taken at the smallest available unit of analysis-individual census blocks and tracts surrounding the intersections where observations took place.

Taken together, these findings lead to the conclusion that at the local level, census data, even if adjusted for the driving age population (age 15 and over), do not provide a reliable benchmark against which the racial composition of motorists stopped by police should be compared.

${ }^{1}$ One way to overcome the problem of nonresident drivers is to use only residents stopped by police when making comparisons to static residential data such as the census. Besides potentially eliminating a large proportion of stops from the analysis, such an approach does not take into account the differences in driving patterns among whites and minorities (see discussion on following page). 


\section{Licensed Drivers}

Using the static population of licensed drivers living in an area as a benchmark is also problematic. As with the census, data on individuals living in a particular location who possess a driver's license cannot serve as a reliable benchmark because such data do not take into account differences in driving patterns among racial groups, nor do they account for in- and out-migration of residents. As others have previously noted (Engel, Calnon, \& Bernard, 2002; Smith \& Alpert, 2002), national surveys indicate substantial differences among blacks and whites in vehicle ownership rates, use of public transportation, miles driven, and motor vehicle trip frequency and duration. Independent of the smaller percentage of blacks compared to whites who possess driver's licenses (Langan, Greenfeld, Smith, Durose, \& Levin, 2001), these data suggest that in the aggregate, fewer blacks may be found on the roadways than their percentage in the licensed driver population would suggest. If adjustments are not made to the recorded number of stops (the numerator) so that only stops of residents are included in the analysis (see footnote 1 ) then existing discrepancies are exacerbated as a residential population is compared to a driving population that may consist substantially of nonresidents. In the end, and for many of the same reasons, using the population of licensed drivers as a benchmark offers only a minimal improvement over the census. If a comparison of the two numbers (the numerator and the denominator) is to make sense, the denominator must represent or estimate the total number of drivers who are available to be stopped because the numerator tells us which drivers have been selected and stopped.

\section{Suspects and Arrestees}

The premise of using the racial composition of those arrested or reported to the police as criminal suspects as a benchmark is based on the belief that police stops should reflect the populations most at risk of engaging in criminal behavior. In the New York Attorney General's (1999) report on the stop and frisk practices of the New York City Police Department, researchers controlled for the differential involvement of minorities in crime (as measured by arrest rates) and still found an increased likelihood that minorities would be stopped by the police. However, in their analysis of traffic stops in Richmond, Virginia, Petrocelli, Piquero, and Smith (2003) found that when stops were aggregated at the census tract level, the Part I crime rate strongly predicted the rate of stops per 1,000 residents, even after controlling for other relevant variables, including the percentage of black population and measures of poverty and unemployment.

It is possible that using proxies for differential criminal involvement as a benchmark makes more sense in studies of police pedestrian stops than it does for traffic stops, given that pedestrian stops must be based on reasonable suspicion that a crime has or is about to occur (Terry $v$. Obio, 1968). Although the same criteria can apply in traffic stops, most traffic stops are reportedly made for 
traffic or vehicle-related infractions and not for suspected criminal involvement (California Highway Patrol, 2000; Connecticut Division of Criminal Justice, 2000; Greenwald, 2001; Missouri Attorney General's Office, 2000; San Diego Police Department, 2000; San Jose Police Department, 1999; Smith \& Petrocelli, 2001; Washington State Patrol, 2001). Accordingly, using data on the racial composition of criminal arrestees or suspects to compare against traffic stops is not analytically sound. To use a well-worn analogy, such an analytic strategy is akin to comparing apples to oranges.

\section{Traffic and Violator Observations}

Currently, the best way to estimate the population of drivers available to be stopped is to observe and count them on the roadways (Smith \& Alpert, 2002). There are questions as to whether the measure is the driving population or the population that is violating traffic laws. Lamberth (1994, 1997), Zingraff et al. (2000), and Lange, Blackman, \& Johnson (2001) all used roadway observers (or cameras) to record information on the race, and in some cases ethnicity, of drivers and speeders. In the ongoing racial profiling study in Miami-Dade County, we used observers to record race data on drivers and a broader class of violators that included speeders, those running red lights, and those making illegal turns. The purpose of collecting data on both drivers and violators is to determine whether individuals of certain racial groups commit observed traffic violations at greater rates than others, a finding which may help explain why police stop some racial groups disproportionately to their respective percentages in the driving population.

As to who commits traffic infractions, Lamberth $(1994,1997)$ found no differences in the rates at which blacks and whites exceeded the speed limit in his observational studies. However, Lamberth defined speeding at a low threshold one mile per hour over the speed limit in one study, and five miles per hour over the speed limit in another. In contrast, Lange et al. (2001) found that blacks on the New Jersey Turnpike were more likely than whites to speed in $65 \mathrm{mph}$ zones but not in $55 \mathrm{mph}$ zones. Sufficient data are not yet available to assess the differences, if any, between racial groups with respect to other traffic infractions.

Despite its advantages over other benchmarks, observational data have their own limitations. First, field observation of drivers and traffic violators is labor intensive and can be expensive. It is for these reasons that only a handful of wellfunded studies have gathered observational data. Second, because of the expense involved, only a limited number of locations are typically observed within the jurisdiction under study, and they are selected for specific reasons (i.e., they are not chosen randomly). Thus, the data cannot be generalized to the driving or violating population of the jurisdiction as a whole, or even to other areas or roadway types that were not observed. In the Miami-Dade study, for example, we chose 11 intersections for observation, but we cannot generalize our findings, even to other intersections, because our sample was not large enough, and, 
additionally, because it was not randomly chosen from all available intersections. These limited data are therefore conclusive only for the time and place studied.

Third, traffic observations are limited according to the visual capabilities of the observers. Although black and non-black drivers can usually be distinguished in the proper lighting conditions, ethnic distinctions can be difficult or impossible to make with an acceptable degree of measurement validity. Even in situations in which drivers are stopped and observers have an opportunity to see them clearly, in south Florida it is highly unlikely that an observer can distinguish a "Hispanic" from a member of another ethnic group. The Hispanic population in south Florida is largely composed of Cuban-Americans and other Hispanics with visible facial features and complexion indistinguishable from other non-black citizens, making this type of identification of a person driving by an observer virtually impossible. In either case, attempting to observe and identify ethnic characteristics of drivers is an exercise fraught with imprecision both for researchers and police officers. Research bears out the existence of such problems. Hispanics are often difficult to identify by both insiders and outsiders (Bean \& Tienda, 1987; Itzigsohn, 1998; Bureau of Justice Statistics, 2003). Indeed, the failure of Hispanics in recent experimental psychological research to pick out fellow co-ethnics in public places shows the significant problems any observer would have identifying a Hispanic driver (Denton \& Massey, 1989). The term "Hispanic" is a designation of the United States Census Bureau and encompasses individuals from across Latin America, the Caribbean, the United States, and parts of Europe. The diverse backgrounds, cultures, histories, and genetic stocks of those who comprise this ethnic category in the United States has produced a group that exhibits considerable variation in its language and appearance. What is more, recent evidence of increasingly high rates of intermarriage between Hispanics and whites in major metropolitan areas makes it likely that physical distinctiveness will be further diluted in generations to come (Farley, 1996).

Although some racial profiling researchers have attempted to count Hispanics, Asians, or Native Americans in the driving population, to our knowledge no attempts have ever been made to validate those observations. Overall, the weight and findings from social research lead to the inescapable conclusion that attempts to conduct systematic or "scientific" observations on the Hispanic population in natural settings is untenable as a research strategy.

Consequently, in the Miami-Dade study, we chose to record observed driver or violator race as a dichotomous variable only-black or non-black-because of the evidence that finer racial or ethnic distinctions cannot be made accurately. Similarly, observations are unreliable at night. Our experiences in Miami-Dade and the experiences of other researchers (Greenwald, 2001) suggest that field observations cannot be carried out reliably in the darkness. As a result, observation data will be biased toward daylight hours. Although one study using 1970-1980 data found differences in daytime and nighttime driving populations among older drivers 
(Stutts \& Martell, 1991), this finding has not been replicated and it is not clear whether these differences would be found in a sample including all age groups.

Given the severe limitations of static benchmarks (census, licensed drivers, or other unchanging measures) and the lack of comparability between traffic stop data and arrest or suspect information, field observation data are left as the only external benchmark currently known to be reliable within the limitations discussed above. However, the cost and expertise required to design and carry out a valid traffic observation study prevents the widespread use of this methodology. In its place or as a supplement, the law enforcement and research communities need an affordable, reliable, and generalizable estimate of the driving population against which most police traffic stops within a given jurisdiction can be compared.

\subsection{Toward a Better Benchmark}

The purpose of establishing a benchmark is to have a reliable measure of drivers who are available to be stopped by the police. Fridell (2004) has noted that people who drive more, drive poorly, and drive to locations where stopping behavior by the police is high are at greater risk of being stopped than other drivers. A proper benchmark will estimate the demographic profile of individuals who will be stopped assuming that no bias exists in police stopping behavior. Actuarial statisticians and traffic safety engineers have conducted research that is relevant to this question. These investigators have used automobile crash data to establish the relative risks of causing a crash or being a crash victim that are associated with driver characteristics, types of vehicles, and roadway conditions, among other factors. Thus, research on the demography of drivers and the violation of traffic laws has been a topic of interest for almost 70 years (Allport, as cited in Ross, 1961). This research has an interesting history. It began with Feest (1968), who reported a study conducted in Berkeley, California, that indicated that the most frequent violation of an intersection controlled by a stop sign is made by drivers who are turning right and are at the least risk of collision (compared to a left turn or going straight). One of his most interesting findings is that only $14 \%$ of all motorists made a full stop at the stop sign when not forced to stop because of traffic. He reported that blacks were slightly more compliant at stop signs than whites $(15 \%$ vs. $11 \%)$ and that whites were much more likely than blacks not to stop or to make half-stops at stop signs (23\% vs. $13 \%)$. Blacks, however, were more likely to roll through stops than whites (72\% vs. 66\%). As noted by McKelvie and Schamer (1988), "Rather than obeying the law, drivers seem to evaluate the risk of violation and then to act accordingly" (p. 685). Risks may include the ability to see, based upon relative darkness, the location of other vehicles, or the presence of passengers. In any case, this early research suggested the importance of studying traffic behavior and identified differences in the driv- 
ing behavior of black and white drivers. These research efforts, however, did not address the relative risk or crash exposure of driving subpopulations.

At about the same time Feest was reporting the results from his Berkeley study, Thorpe (1967) moved beyond the observation of driving violations and developed likelihood estimates of driver involvement in crashes. He calculated the number of crashes relative to the drivers' exposure to traffic. Thorpe's model made some unsupported assumptions about exposure, but his important insights and ideas set the foundation upon which others could build. Carr (1969), for example, introduced the idea of identifying the at-fault driver in a multiple vehicle crash by using police accident investigation reports, which was later labeled quasi-induced exposure by Haight (1970). Carr's (1969) exposure model compares the proportion of the responsible population (at-fault drivers) to the proportion of the non-responsible population (not-at-fault drivers) within categories of drivers. This methodology has been used in the traffic safety literature to estimate the crash risk of drivers grouped by age (McKelvey \& Stamatiadis, 1988), the impact of age on specific traffic maneuvers (Staplin \& Lyles, 1991), and the cause of crashes (Stamatiadis \& Deacon, 1997), among others things.

Underlying the quasi-induced exposure method is the theoretical assumption that not-at-fault drivers in two-vehicle crashes represent a random sample of the driving population (Kirk \& Stamatiadis, 2001; Koornstra, 1973; Stamatiadis \& Deacon, 1997). As Stamatiadis (2002) later asserted, "If you are hitting another vehicle, you do not select the driver based on age, gender, race, etc. but you hit whoever happens to be there." If Stamatiadis and the other safety engineers are correct in their assertion that not-at-fault drivers in two-car crashes represent the driving population, then the racial composition of not-at-fault crash victims should approximate the racial composition of observed drivers and could act as a relatively inexpensive and readily available denominator for research on topics where a baseline of drivers is needed, including research on racial profiling.

\section{Empirical Tests of the Quasi-Induced Exposure Method}

Although the quasi-induced exposure method has never been tested or applied in the context of racial profiling research, it has been subjected to limited empirical testing in other contexts. Stamatiadis and Deacon (1997) used crash data in Kentucky from 1990-1992 to determine the association, if any, between age groupings of at-fault and not-at-fault drivers. They found that within some categories, individuals of similar ages tended to get into crashes more frequently than expected, and for other age categories, individuals of similar ages tended to get into fewer crashes than expected. In particular, older at-fault drivers (age 55 and above) were overinvolved in crashes with not-at-fault drivers of similar ages. They concluded that at-fault and not-at-fault drivers of similar ages probably exhibited similar travel patterns, which would account for the association between age 
groupings. The analysis demonstrates that at least for some categories of drivers, crash data alone cannot be used to determine whether not-at-fault drivers represent a random sample of the driving population because those drivers will cluster with similar categories of at-fault drivers and thus will not appear evenly distributed across at-fault driver categories.

However, associations between categories of at-fault and not-at-fault drivers may vary according to the categories selected. DeYoung, Peck, and Helander (1997) conducted a category-type analysis using six years (1987-1992) of fatal crash data from California. They compared the distribution of crashes involving three categories of at-fault drivers-those with valid driver's licenses, those with suspended driver's licenses, and those without licenses- to the distribution of crashes involving the same categories of not-at-fault drivers. If not-at-fault drivers represent a random sample of the driving population, then a given category of at-fault drivers should show approximately the same proportion of crash victims within each category as not-at-fault drivers (suspended, valid, unlicensed), assuming that at-fault and not-at-fault drivers within the same categories do not exhibit similar driving patterns. Of course, this assumption was not met in the Stamatiadis and Deacon (1997) data, which showed correlations between agerelated categories of at-fault and not-at-fault drivers.

In contrast, the California fatal crash data showed no statistically significant differences in the proportions within each category of not-at-fault drivers struck by at-fault drivers. Thus, licensed, at-fault drivers struck licensed drivers $90 \%$ of the time, while suspended and unlicensed at-fault drivers struck licensed drivers $85 \%$ and $84 \%$ of the time, respectively. Again, these small percentage point differences were not statistically significant in any of the categories, indicating that at least with respect to licensed, suspended, and unlicensed categories of drivers, not-at-fault crash data may provide a close approximation of how those groups are represented in the driving population.

Similarly, Lyles, Stamatiadis and Lighthizer (1991) examined 1988 crash data from the State of Michigan to determine whether age and gender groupings of at-fault and not-at-fault drivers were associated. They found that in two-vehicle crashes, male and female at-fault drivers struck male and female drivers (crash victims) proportionately. For example, $66.8 \%$ of victims struck by male at-fault drivers were males, while $33.2 \%$ of victims were females. Similarly, for female at-fault drivers, $65.3 \%$ of their victims were males, and $34.7 \%$ were females. The small differences between the victims struck by male and female at-fault drivers were not statistically significant. Based on these and similar findings broken down by roadway type, vehicle type, and age groupings, Lyles et al. (1991) concluded that not-at-fault drivers in two-vehicle crashes represent "a random sample of all those on the road under the specified conditions [males vs. females]otherwise they would not be expected to be similar" (p. 284).

As the subsequent Stamatiadis and Deacon (1997) age category analysis showed, however, crash data themselves may not be sufficient to answer the 
question of whether not-at-fault crash victims represent a random sample of the driving population. Because certain categories of not-at-fault drivers are associated with similar categories of at-fault drivers does not mean that crash victims do not approximate the driving population as a whole. Such findings may simply mean, as Stamatiadis and Deacon (1997) suggest, that similar categories of atfault and not-at-fault drivers exhibit similar travel patterns and thus are more likely to be involved in crashes with one another. In order to more accurately assess the validity of the quasi-induced exposure method, another source of data external to the crash data themselves must be identified. The characteristics of not-at-fault drivers (or their vehicles) must be compared to these data in order to determine whether they approximate the characteristics of the driving population.

To begin to address the deficiency of relying solely on the crash data themselves to test the quasi-induced method, Stamatiadis and Deacon (1997) also used data on truck-involved crashes to ascertain whether the percentage of crashes involving trucks was associated with the percentage of trucks traveling on Kentucky roadways as measured by classification counts taken at representative locations. According to the Kentucky data, straight trucks were involved in $3.1 \%$ of crashes and constituted $3.2 \%$ of observed vehicles according to the classification counts. For combination trucks, the figures were $6.2 \%$ and $6.8 \%$, respectively. $^{2}$ Thus, the crash data closely approximated the percentage of trucks traveling the roadways as determined from classification counts and offered support for the validity of the quasi-induced method.

Subsequently, Kirk and Stamatiadis (2001) attempted to further explore the exposure method by using trip diaries, or records of when and where people drove, to develop travel estimates among a sample of Fayette County, Kentucky, residents. Data from 26 completed diaries were extrapolated to the population of licensed drivers in Fayette County and were then compared to 1996-1998 Fayette County traffic crash records maintained in the Kentucky Crash Record System. Applying the exposure method, the not-at-fault drivers from two-vehicle crashes were used as the benchmark (or exposure metric) against which the trip diary data were compared.

Comparisons were carried out for three age groups (18-34, 35-64, and over 64), five roadway types (interstate, major arterial, minor arterial, collectors, and local roads), and two time periods (daylight and nighttime). The results indicated that the diary-based data and traffic crash data were most similar among the $35-64$ age group- $53 \%$ of kilometers traveled versus $44 \%$ of not-at-fault crash victims. Among this age group, kilometers traveled (as derived from the trip diaries) was most comparable to not-at-fault crash data on roads designated as collectors- $43.6 \%$ of kilometers traveled versus $44.5 \%$ of not-at-fault crash

${ }^{2}$ Stamatiadis \& Deacon did not define the terms “straight truck" or "combination truck." 
victims. Differences were greater for other age groups and other roadway types, particularly interstates.

Given the small number of subjects involved in the trip diary project, further empirical validation of the exposure method is clearly required before not-atfault crash data can be accepted as a proxy for the driving population. However, the few studies that have attempted to validate the method have shown that it holds promise as a potentially useful metric for approximating relevant characteristics of the driving population within a geographic area of interest. If this method can be further validated as a reliable estimation of the racial composition of drivers, then not-at-fault crash data can serve as an alternative and potentially superior benchmark against which researchers can compare police traffic stop data.

\section{(2) A First Test of DPEM}

The purpose of this section is to explain our test of the Driving Population Estimation Measure (DPEM). As part of a larger and ongoing study of racial profiling in Miami-Dade County, Florida, we collected traffic pattern data from 11 selected intersections in unincorporated Miami-Dade County during fall and winter 2002. Observation data from these intersections were later compared to not-at-fault traffic crash data from the same intersections.

Intersections were selected specifically for their high traffic and crash volumes and the racial make-up of the area. As the determination of driver ethnicity is problematic (see discussion above), recorded categories of drivers were limited to black and non-black. Observers were trained to look for skin color and to code drivers accordingly. Attempts to discern finer racial characteristics (e.g., Hispanic, Asian) were not made. Thus, individuals with light skin and who did not appear black were coded as non-black.

Consistent with the goals of the larger study (see discussion below), a list of intersections in predominantly non-black, substantially black, and racially mixed areas of unincorporated Miami-Dade County was compiled by the Miami-Dade Police Department. Within these areas, which encompassed all eight police districts, 11 high volume crash locations and five Buckle-Up Florida Campaign seat belt observation locations were chosen as observation sites for our larger study. At one time, the Buckle-Up Florida intersections were used to monitor seatbelt compliance and served as convenient and well-tested observation locations. Data on traffic and crash volumes at the remaining intersections were provided by the police department and were used to identify the high volume intersections. For the purposes of this analysis, however, the Buckle-Up Florida sites were eliminated because of their low volume of traffic crashes, leaving 11 sites to serve as the sample for the analyses described below.

Each intersection was observed by teams of three observers during the morning and evening for four hours each, for a total of eight hours. The days of the 
observations were varied throughout the week, except that Sundays were excluded. The morning observations were conducted from 9 a.m. to 1 p.m. and included some rush hour traffic. The evening observations took place between 4 p.m. and 8 p.m. and also included both rush hour and non-rush hour traffic. Traffic observations at the intersections began in mid-August 2001 and concluded in mid-February 2002. Night observations were not conducted because of the difficulty in determining the race of drivers after dark. When the observers could not determine the race or gender of the driver, the category of unknown was used. In only $1.7 \%$, or 1,585 of the observations, could the race or gender of the driver not be determined. There was a combined total of 65,025 successful observations at the 11 intersections. Of those drivers observed, 16,937 (26\%) were black, and 48,088 (74\%) were non-black. These observations were distributed across the 11 intersections, which, again, were located within predominantly non-black, substantially black, and racially mixed areas. The observation data from these sites were used to test the DPEM method by comparing them to the baseline data created by the not-at-fault drivers in two-car crashes.

Unfortunately, the race of drivers involved in traffic crashes is not computerized in Miami-Dade County. Thus, data on driver race were manually extracted from the original Florida Traffic Crash Reports maintained by the police department. These included the race of drivers as well as the responsible party, as determined by the investigating police officer. Available race and ethnic categories on the crash reports included black, white, Hispanic, and other. For consistency with the observational strategy, driver race was coded as black or non-black. Thus, the non-black category combined the white, Hispanic, and other categories from the crash reports. Crash data were collected for crashes that occurred at the 11 high volume intersections for the first six months of 2001. For the analyses that follow, and consistent with the theoretical foundation of the quasi-induced exposure method, the race of the not-at-fault driver in two-car crashes was recorded. Overall, 403 crash records were reviewed and coded. Seventy-eight percent (316) of the victims were non-black and $22 \%$ (87) of the victims were black.

\section{Three Levels of Analysis}

Traffic observation and crash data were compared at three different levels of aggregation. The first level of analysis disaggregated the data by each of the 11 intersections so that similarities and differences could be noted among the different sites. As noted below, disaggregating the data at the intersection level produced the greatest differences between observations and the not-at-fault crash data; when aggregated, these differences were not statistically significant.

The second level of aggregation combined data from all of the intersections into one analysis. Previous researchers have advocated aggregating crash data in various ways: by geography (urban vs. rural), roadway type, time of day, and day of the week, among others (Lyles, Stamatiadis, \& Lighthizer, 1991; Stamatiadis \& Deacon, 1997). The crash and observation data in this study all came from 
high traffic, high crash volume intersections. Although the intersections were not selected randomly from all available intersections of this type, they share the common characteristic of being heavily traveled locations with a relatively large number of motor vehicle crashes. Thus, the data lend themselves to an aggregate analysis that is naturally grouped according to this type of intersection.

Finally, the data were aggregated according to the racial composition of the area in which the intersections were located. The purpose of this area-level focus in the larger racial profiling study was to determine if traffic patterns and police traffic stop behavior differed according to the racial composition of the areas where traffic stops occurred. Thus, we grouped the 11 intersections into three categories according to the racial composition of the areas surrounding them. In this way, intersections (and their associated observation and crash data) were categorized as being located in predominantly non-black, substantially black, or racially mixed areas. Aggregation by the racial composition of the area surrounding the intersections allowed for a more meaningful contextual analysis while still retaining sufficient analytical power for statistical purposes. Moreover, for reasons that we explain later, grouping intersections by racial composition mitigates the possibility that traffic crashes are not uniformly dispersed across neighborhoods.

\section{Defining the Racial Makeup of the Neighborhoods}

In conducting the area-level analysis, four separate criteria were considered for determining the racial composition of the areas where the intersections are located. The first criterion was the characterization of the neighborhood by police officials working with us on the racial profiling study. This characterization is potentially important because it captures the way that police think about the areas in which they operate. The second and third criteria were the racial composition of census blocks and the tracts where the intersections are located. These criteria reflect the racial composition of the immediate (block-level) area and the general area (tract) surrounding each intersection. The fourth criterion was our own data on the race of drivers observed at the intersections. This captures the racial makeup of the drivers in the area, which may vary somewhat from the police characterizations or the demographic composition of the residents in the area.

Because it is important to consider that citizens who live in an area are likely to drive through high volume intersections located in close proximity to their residences, we chose to categorize an intersection as predominantly non-black, substantially black, or racially mixed, primarily according to the racial composition of the census tract where the intersections are located. Unlike census blocks, census tracts are large enough to capture the character of the area surrounding the intersections, which might (and often did) include neighborhoods whose racial composition was substantially different from that of the intersection itself. Our goal was to capture not just those who lived immediately adjacent to the 
intersections but also individuals who lived close by and who might possibly travel through them as part of their daily routine.

Our demographic analysis was based on census figures for the year 2000. These figures indicate that the overall black population in Miami-Dade County is $20.3 \%$, and the overall non-black population is slightly less than $80 \%$. After a careful analysis of the demographic characteristics of the county and individual areas, we adopted a $10 \%$ over-under margin technique to identify areas with significantly distinct racial characteristics. For our analysis, an area with a $s u b$ stantial black population is one with $30 \%$ or more black residents- $10 \%$ above the overall county population of $20 \%$ black. Similarly, we have defined predominantly non-black areas as those with $90 \%$ or more non-black residents. Mixed areas are those that do not qualify as substantially black or predominantly nonblack and which have fewer than 30\% black residents and less than $90 \%$ nonblack residents.

One problem in labeling an area non-black, black, or racially mixed arises when there is a difference between the racial proportions of observed drivers at an intersection and the proportion of residents in the larger census tract that includes the intersection. In two cases-intersections 5 and 7-the proportion of observed black drivers exceeded the proportion of blacks in the surrounding census tract by a magnitude of three or four. In these cases, when the two measures produced different characterizations, we chose to label the intersections as racially mixed on the premise that the areas were not sufficiently distinct to be characterized as black or non-black under our $10 \%$ over-under aggregation scheme. (The racial characterization data for all intersections are presented in Table 3.)

\section{Findings}

As described above, our first analysis compares observation to crash data by race for each of the 11 intersections. The data from Table 1 show some differences between the percentage of drivers observed by racial category (black and non-black) and the percentage of not-at-fault crash victims at the intersections. The difference in 9 of the intersections is relatively small. However, at 2 intersections, which are in substantially black neighborhoods, the difference in observed drivers and crash victims is larger. For the first of these 2 intersections (site 10), there is a higher proportion of non-black drivers, but a larger proportion of black crash victims. For the second of the 2 intersections, (site 11), there is a higher proportion of black drivers, and a higher proportion of non-black crash victims. Whether these differences remain significant when the data are aggregated is discussed below.

Table 2 shows the number and percentages of observations and crashes by race of individual for all 11 intersections combined. The data indicate a 4 percentage-point difference between the proportion of drivers observed (black and nonblack) and the proportion of those involved in traffic crashes as victims. The differences noted in Table 1 were tested for statistical significance using a difference 
2.2. Table 1

Comparison of Observed Driver Race and Not-at-Fault Crash Victim Race at 11 Intersections

\begin{tabular}{|c|c|c|c|c|c|}
\hline \multirow[b]{2}{*}{ Intersection } & \multicolumn{2}{|c|}{ Observed Driver Race } & \multicolumn{2}{|c|}{ Crash Victim Race } & \multirow{2}{*}{$\begin{array}{c}\text { Difference } \\
\% \text { Obs.-Crash } \\
\end{array}$} \\
\hline & Non-Black & Black & Non-Black & Black & \\
\hline $\begin{array}{l}\text { 1. } 104 \text { St \& } \\
\text { SW } 137 \text { Ave }\end{array}$ & $\begin{array}{c}2,733 \\
(92 \%)\end{array}$ & $\begin{array}{r}225 \\
(8 \%)\end{array}$ & $\begin{array}{r}29 \\
(97 \%)\end{array}$ & $\begin{array}{r}1 \\
(3 \%)\end{array}$ & $5 \%$ \\
\hline $\begin{array}{l}\text { 2. } 26 \text { St \& } \\
\text { SW } 127 \text { Ave }\end{array}$ & $\begin{array}{r}2,338 \\
(98.5 \%)\end{array}$ & $\begin{array}{r}35 \\
(1.5 \%)\end{array}$ & $\begin{array}{r}21 \\
(96 \%)\end{array}$ & $\begin{array}{r}1 \\
(4 \%)\end{array}$ & 2.5 \\
\hline $\begin{array}{l}\text { 3. } 41 \text { St \& } \\
\text { NW } 107 \text { Ave }\end{array}$ & $\begin{array}{r}6,324 \\
(90 \%)\end{array}$ & $\begin{array}{r}729 \\
(10 \%)\end{array}$ & $\begin{array}{r}22 \\
(92 \%)\end{array}$ & $\begin{array}{r}2 \\
(8 \%)\end{array}$ & 2 \\
\hline $\begin{array}{l}\text { 4. } 152 \text { St \& } \\
\text { SW } 137 \text { Ave }\end{array}$ & $\begin{array}{r}6,389 \\
(84 \%)\end{array}$ & $\begin{array}{l}1,229 \\
(16 \%)\end{array}$ & $\begin{array}{r}51 \\
(84 \%)\end{array}$ & $\begin{array}{r}10 \\
(16 \%)\end{array}$ & 0 \\
\hline $\begin{array}{l}\text { 5. } 88 \text { St \& } \\
\text { SW } 107 \text { Ave }\end{array}$ & $\begin{array}{c}6,818 \\
(89 \%)\end{array}$ & $\begin{array}{r}857 \\
(11 \%)\end{array}$ & $\begin{array}{r}28 \\
(97 \%)\end{array}$ & $\begin{array}{r}1 \\
(3 \%)\end{array}$ & 8 \\
\hline $\begin{array}{l}\text { 6. } 72 \text { St \& } \\
\text { SW } 137 \text { Ave }\end{array}$ & $\begin{array}{r}3,932 \\
(94 \%)\end{array}$ & $\begin{array}{r}242 \\
(6 \%)\end{array}$ & $\begin{array}{r}25 \\
(93 \%)\end{array}$ & $\begin{array}{r}2 \\
(7 \%)\end{array}$ & 1 \\
\hline $\begin{array}{l}\text { 7. } 79 \text { Ave \& } \\
\text { NW } 36 \mathrm{St}\end{array}$ & $\begin{array}{r}3,028 \\
(86.5 \%)\end{array}$ & $\begin{array}{r}473 \\
(13.5 \%)\end{array}$ & $\begin{array}{r}57 \\
(85 \%)\end{array}$ & $\begin{array}{r}10 \\
(15 \%)\end{array}$ & 1.5 \\
\hline $\begin{array}{l}\text { 8. } 119 \text { St \& } \\
\text { NW } 27 \text { Ave }\end{array}$ & $\begin{array}{l}1,802 \\
(45 \%)\end{array}$ & $\begin{array}{r}2,166 \\
(55 \%)\end{array}$ & $\begin{array}{r}16 \\
(49 \%)\end{array}$ & $\begin{array}{r}17 \\
(51 \%)\end{array}$ & 4 \\
\hline $\begin{array}{l}\text { 9. } 36 \text { St \& } \\
\text { NW } 72 \text { Ave }\end{array}$ & $\begin{array}{l}6,256 \\
(89 \%)\end{array}$ & $\begin{array}{r}781 \\
(11 \%)\end{array}$ & $\begin{array}{r}41 \\
(84 \%)\end{array}$ & $\begin{array}{r}8 \\
(16 \%)\end{array}$ & 5 \\
\hline $\begin{array}{r}\text { 10. } 167 \text { St \& } \\
\text { NE } 6 \text { Ave }\end{array}$ & $\begin{array}{r}7,209 \\
(50 \%)\end{array}$ & $\begin{array}{l}7,097 \\
(50 \%)\end{array}$ & $\begin{array}{r}8 \\
(28 \%)\end{array}$ & $\begin{array}{r}21 \\
(72 \%)\end{array}$ & 22 \\
\hline $\begin{array}{l}\text { 11. } 79 \text { St \& } \\
\text { NW } 27 \text { Ave }\end{array}$ & $\begin{array}{l}1,259 \\
(29 \%)\end{array}$ & $\begin{array}{l}3,103 \\
(71 \%)\end{array}$ & $\begin{array}{r}18 \\
(56 \%)\end{array}$ & $\begin{array}{r}14 \\
(44 \%)\end{array}$ & 27 \\
\hline
\end{tabular}

Table 2

Aggregate Comparison of Driver Race by Observation and Crash Victim Data at 11 Intersections

\begin{tabular}{|c|c|c|c|}
\hline & Observed Driver Race & CrashVictim Race & $\begin{array}{c}\text { Difference } \\
\text { (Obs.-Crashes) }\end{array}$ \\
\hline Black & $\begin{array}{r}16,937 \\
(26 \%)\end{array}$ & $\begin{array}{r}87 \\
(22 \%)\end{array}$ & $4 \%$ \\
\hline Non-Black & $\begin{array}{r}48,088 \\
(74 \%)\end{array}$ & $\begin{array}{r}316 \\
(78 \%)\end{array}$ & $4 \%$ \\
\hline Total & $\begin{array}{r}65,025 \\
(100 \%)\end{array}$ & $\begin{array}{r}403 \\
(100 \%)\end{array}$ & \\
\hline
\end{tabular}


between proportions test, which divides the difference between the proportions of two samples (black crashes and black observations) by the standard error of the difference in proportions. For large samples, this test produces a $\mathrm{z}$ statistic, which can be compared to the critical value $(\alpha=.05)$ under the standard normal curve. In this case, the difference of 4 percentage points between crashes and observations for all intersections was not statistically significant $(z=1.83)$.

Our final analysis focuses on three different types of areas: predominantly non-black, racially mixed, and substantially black. Table 3 shows how the police

\section{Table 3}

Racial Characteristics of the Neighborhoods Surrounding the Observed Intersections

\begin{tabular}{cccccc} 
& Police Dept. & $\%$ Black & $\%$ Black & \% Black & Classification \\
\cline { 3 - 4 } & Definition & Residents & Residents & Drivers & $10-29 \%$ Mixed \\
Intersection & of Area & Census Block & Census Tract & Observed & $30 \%+$ Black \\
\hline
\end{tabular}

1. 104 St $\&$

$\begin{array}{lllll}\text { SW } 137 \text { Ave } & \text { Non-Black } & 5 \% & 7 \% & 8 \%\end{array}$

2. 26 St $\&$

SW 127 Ave Non-Black $\quad 3 \quad<1 \quad 1 \quad$ Non-Black

3. 41 St $\&$

NW 107 Ave Mixed

22

10

Non-Black

4. 152 St \& SW 137 Ave

Mixed

11

11

16

Mixed

5. 88 St $\&$ SW 107 Av

Mixed

4

4

11

Mixed $^{b}$

6. 72 St $\&$

SW 137 Ave Mixed

2

3

6

Non-Black

7. 79 Ave $\&$ NW $36 \mathrm{St}$

Mixed

5

3

14

Mixed $^{b}$

8. 119 St \& NW 27 Ave

Mixed

83

68

55

Black

9. 36 St $\&$ NW 72 Ave

Mixed

1

12

11

Mixed

10.167 St \&

NE 6 Ave

Mixed

34

31

50

Black

11.79 St \& NW 27 Ave

Black

13

41

71

Black

a The classification scheme is described in the section Defining the Racial Makeup of the Neighborhoods.

b When the two measures produce different characterizations, it is clear that the area is not sufficiently distinct to be characterized as one or the other. 
defined the area surrounding each intersection, the racial composition of the residential population, and the racial breakdown of the traffic observations at each site. Based on our area classification methodology previously described, sites $1,2,3$, and 6 are in predominantly non-black areas, sites 4, 5, 7, and 9 are in racially mixed areas, and sites 8,10 , and 11 are in substantially black areas (see column 6). Within this three-fold neighborhood context, we examine both the proportion of drivers observed and the proportion of crash victims, across both black and non-black subjects.

Table 4 presents the number and proportion of drivers observed by race and gender groups at the 11 intersections. The data in Table 5 show the race of not-at-

(2.20 4

Number and Proportion of Drivers Observed by Race and Gender at Intersections

\begin{tabular}{|c|c|c|c|c|c|c|}
\hline \multirow[b]{2}{*}{ Intersection } & \multirow{2}{*}{$\begin{array}{c}\text { Neighborhood } \\
\text { Type }\end{array}$} & \multicolumn{2}{|c|}{ Non-Black } & \multicolumn{2}{|c|}{ Black } & \multirow[b]{2}{*}{ Total } \\
\hline & & Males & Females & Males & Females & \\
\hline $\begin{array}{l}\text { 1. } 104 \text { St \& } \\
\text { SW } 137 \text { Ave }\end{array}$ & Non-Black & $\begin{array}{r}1,680 \\
(57 \%)\end{array}$ & $\begin{array}{r}1,053 \\
(35 \%)\end{array}$ & $\begin{array}{r}127 \\
(4 \%)\end{array}$ & $\begin{array}{r}98 \\
(3 \%)\end{array}$ & 2,958 \\
\hline $\begin{array}{l}\text { 2. } 26 \text { St \& } \\
\text { SW } 127 \text { Ave }\end{array}$ & Non-Black & $\begin{array}{l}1,137 \\
(48 \%)\end{array}$ & $\begin{array}{r}1,201 \\
(51 \%)\end{array}$ & $\begin{array}{r}20 \\
(1 \%)\end{array}$ & $\begin{array}{r}15 \\
(1 \%)\end{array}$ & 2,373 \\
\hline $\begin{array}{l}\text { 3. } 41 \text { St \& } \\
\text { NW } 107 \text { Ave }\end{array}$ & Non-Black & $\begin{array}{r}3,781 \\
(54 \%)\end{array}$ & $\begin{array}{r}2,543 \\
(36 \%)\end{array}$ & $\begin{array}{r}494 \\
(7 \%)\end{array}$ & $\begin{array}{r}235 \\
(3 \%)\end{array}$ & 7,053 \\
\hline $\begin{array}{l}\text { 4. } 152 \text { St \& } \\
\text { SW } 137 \text { Ave }\end{array}$ & Mixed & $\begin{array}{r}3,737 \\
(49 \%)\end{array}$ & $\begin{array}{r}2,652 \\
(35 \%)\end{array}$ & $\begin{array}{r}664 \\
(9 \%)\end{array}$ & $\begin{array}{r}565 \\
(7 \%)\end{array}$ & 7,618 \\
\hline $\begin{array}{l}\text { 5. } 88 \text { St \& } \\
\text { SW } 107 \text { Ave }\end{array}$ & Mixed & $\begin{array}{r}3,749 \\
(49 \%)\end{array}$ & $\begin{array}{r}3,069 \\
(40 \%)\end{array}$ & $\begin{array}{r}550 \\
(7 \%)\end{array}$ & $\begin{array}{r}307 \\
(4 \%)\end{array}$ & 7,675 \\
\hline $\begin{array}{l}\text { 6. } 72 \text { St \& } \\
\text { SW } 137 \text { Ave }\end{array}$ & Non-Black & $\begin{array}{r}2,252 \\
(54 \%)\end{array}$ & $\begin{array}{r}1680 \\
(40 \%)\end{array}$ & $\begin{array}{r}180 \\
(4 \%)\end{array}$ & $\begin{array}{r}62 \\
(1 \%)\end{array}$ & 4,174 \\
\hline $\begin{array}{l}\text { 7. } 79 \text { Ave } \& \\
\text { NW } 36 \mathrm{St}\end{array}$ & Mixed & $\begin{array}{r}1,959 \\
(56 \%)\end{array}$ & $\begin{array}{r}1,069 \\
(31 \%)\end{array}$ & $\begin{array}{r}298 \\
(9 \%)\end{array}$ & $\begin{array}{r}175 \\
(5 \%)\end{array}$ & 3,501 \\
\hline $\begin{array}{l}\text { 8. } 119 \text { St \& } \\
\text { NW } 27 \text { Ave }\end{array}$ & Black & $\begin{array}{l}1,125 \\
(28 \%)\end{array}$ & $\begin{array}{r}677 \\
(17 \%)\end{array}$ & $\begin{array}{r}1,203 \\
(30 \%)\end{array}$ & $\begin{array}{r}963 \\
(24 \%)\end{array}$ & 3,968 \\
\hline $\begin{array}{l}\text { 9. } 36 \text { Str } \& \\
\text { NW } 72 \text { Ave }\end{array}$ & Mixed & $\begin{array}{r}4,571 \\
(65 \%)\end{array}$ & $\begin{array}{l}1,685 \\
(24 \%)\end{array}$ & $\begin{array}{r}528 \\
(8 \%)\end{array}$ & $\begin{array}{r}253 \\
(4 \%)\end{array}$ & 7,037 \\
\hline $\begin{array}{l}\text { 10. } 167 \text { St \& } \\
\text { NE } 6 \text { Ave }\end{array}$ & Black & $\begin{array}{r}4,122 \\
(29 \%)\end{array}$ & $\begin{array}{r}3,087 \\
(22 \%)\end{array}$ & $\begin{array}{r}3,947 \\
(28 \%)\end{array}$ & $\begin{array}{r}3,150 \\
(22 \%)\end{array}$ & 14,306 \\
\hline $\begin{array}{l}\text { 11. } 79 \text { St } \& \\
\text { NW } 27 \text { Ave }\end{array}$ & Black & $\begin{array}{r}767 \\
(18 \%)\end{array}$ & $\begin{array}{r}492 \\
(11 \%)\end{array}$ & $\begin{array}{r}1,660 \\
(38 \%)\end{array}$ & $\begin{array}{r}1,443 \\
(33 \%)\end{array}$ & 4,362 \\
\hline
\end{tabular}


fault driver crash victims in two-car crashes for the intersections. The traffic data demonstrate that blacks drive in substantially black areas, while non-blacks tend to drive through predominantly non-black and racially mixed areas. The crash data show that black citizens are hit most often in substantially black areas but rarely in non-black areas. Non-black crash victims are hit in predominantly non-black and mixed areas but rarely in black areas. The remainder of the analysis will aggregate the data from the individual intersections into racial "types," as explained above.

Table 5

Race of Crash Victims by Neighborhood

\begin{tabular}{|c|c|c|c|c|}
\hline Intersection & $\begin{array}{c}\text { Neighborhood } \\
\text { Type }\end{array}$ & $\begin{array}{c}\text { Non-Black } \\
\text { Crash Victims }\end{array}$ & $\begin{array}{c}\text { Black } \\
\text { Crash Victims }\end{array}$ & Total \\
\hline
\end{tabular}

1. 104 St \& $\quad$ Non-Black $29(97 \%) \quad 1(3 \%) \quad 30(100 \%)$ SW 137 Ave

2. 26 St $\&$

Non-Black

$21(96 \%)$

$1(4 \%)$

$22(100 \%)$ SW 127 Ave

3. 41 St \& NW 107 Ave

Non-Black

$22(92 \%)$

$2(8 \%)$

$24(100 \%)$

4. 152 St \&

Mixed

$51(84 \%) \quad 10(16 \%)$

$61(100 \%)$ SW 137 Ave

5. 88 St $\&$ SW 107 Ave

Mixed

$28(97 \%)$

$1(3 \%)$

$29(100 \%)$

6. 72 St $\&$ SW 137 Ave

Non-Black

$25(93 \%)$

$2(7 \%)$

$27(100 \%)$

7. 79 Ave $\&$ NW $36 \mathrm{St}$

Mixed

$57(85 \%) \quad 10(15 \%)$

$67(100 \%)$

8. 119 St \& NW 27 Ave

Black

$16(49 \%)$

$17(51 \%)$

$33(100 \%)$

9. $36 \operatorname{Str} \&$ NW 72 Ave

Mixed

$41(84 \%)$

$8(16 \%)$

$49(100 \%)$

10. 167 St \&

Black

$8(28 \%)$

$21(72 \%)$

$29(100 \%)$

NE 6 Ave

11. 79 St $\&$ NW 27 Ave

Black

$18(56 \%)$

$14(44 \%)$

$32(100 \%)$

Total

$316(78 \%) \quad 87(22 \%)$

$403(100 \%)$ 
Tables 6 and 7 present the data on crashes and drivers in the different area types and among blacks and non-blacks, respectively. As can be seen from these data, black crash victims are represented in the three types of areas but at significantly different rates. For example, in substantially black areas, 55.3\% of the victims were black, while in predominantly non-black and mixed areas, black drivers made up $5.8 \%$ and $14.1 \%$ of the victims, respectively. When these data are compared to the proportion of black drivers observed across the three area types, the ratios are remarkably similar. For example, $7.4 \%$ of the drivers

Table 6

Difference Between Percent Black Drivers and Percent Black Crash Victims By Area Type

\begin{tabular}{lccc} 
Areas Sampled & $\begin{array}{c}\text { \% Black Drivers } \\
\text { Observed }\end{array}$ & $\begin{array}{c}\text { \% Black Crash } \\
\text { Victims }\end{array}$ & $\begin{array}{c}\text { Percentage Point } \\
\text { Difference }\end{array}$ \\
\hline Predominately & $(1,231 / 16,558)$ & $(6 / 103)$ & $1.6 \%$ \\
Non-Black & $7.43 \%$ & $5.8 \%$ & \\
& & $(52 / 94)$ & $.69 \%$ \\
Substantial & $(12,366 / 22,636)$ & $55.3 \%$ & \\
Black Pop. & $54.6 \%$ & & \\
& & $(29 / 206)$ & $1.15 \%$ \\
Racially Mixed & $(3,340 / 25,831)$ & $14.1 \%$ &
\end{tabular}

Table 7

Difference Between Percent Non-Black Drivers and Percent Non-Black Crash Victims By Area Type

\begin{tabular}{lccc} 
Areas Sampled & $\begin{array}{c}\text { \% Non-Black } \\
\text { Drivers Observed }\end{array}$ & $\begin{array}{c}\text { \% Non-Black } \\
\text { Crash Victims }\end{array}$ & $\begin{array}{c}\text { Percentage Point } \\
\text { Difference }\end{array}$ \\
\hline $\begin{array}{l}\text { Predominately } \\
\text { Non-Black }\end{array}$ & $\begin{array}{c}(15,327 / 16,558) \\
92.57 \%\end{array}$ & $\begin{array}{c}(97 / 103) \\
94.17 \%\end{array}$ & $1.6 \%$ \\
Substantial & $(10,270 / 22,636)$ & $(42 / 94)$ & $.69 \%$ \\
Black Pop. & $45.37 \%$ & $44.68 \%$ & \\
& & $(177 / 206)$ & $1.15 \%$ \\
Racially Mixed & $(22,491 / 25,831)$ & $85.92 \%$ &
\end{tabular}


observed in predominantly non-black areas were black, while $5.8 \%$ of the crash victims were black. In racially mixed areas, black drivers represented $12.9 \%$ of all drivers and $14.1 \%$ of crash victims. Finally, $54.6 \%$ of drivers observed in substantially black areas were black, which compares favorably with the $55.3 \%$ of crash victims in black areas. The percentage point difference across drivers and crash victims in predominantly non-black areas is only $1.6 \%$, while the comparable estimates in mixed and substantially black neighborhoods are $1.2 \%$ and $.69 \%$, respectively.

Among non-black drivers, similar relationships are seen. The data in Table 7 show that in predominantly non-black areas, $94.2 \%$ of the crash victims were non-black. In mixed areas, $85.9 \%$ of the victims were non-black, while in substantially black neighborhoods, $44.7 \%$ of the victims were non-black. When these estimates are compared to the proportion of non-black drivers observed across the three neighborhoods, the figures are very similar. Non-blacks comprised $92.6 \%$ of all drivers observed in predominantly non-black areas and $94.2 \%$ of crash victims in these areas. In racially mixed areas, $87.1 \%$ of all drivers observed were non-black, while $85.9 \%$ of crash victims were non-black. In substantially black neighborhoods, the difference between the percentage of non-black drivers observed and non-black crash victims was only .69\%. Taken together, the data on non-black drivers and crash victims are remarkably similar across the three types of neighborhoods.

\section{(20nclusions}

In this research, we build upon the quasi-induced exposure method in developing a Driving Population Estimation Measure (DPEM). This measure uses notat-fault traffic crash victims to estimate the racial and ethnic composition of the driving population. When two-vehicle traffic crash data from 403 crashes at 11 high crash intersections in unincorporated Miami-Dade County were aggregated to area type (black, non-black, racially mixed) and compared against more than 65,000 traffic observations, the percentage point difference across drivers and crash victims in predominantly non-black areas was only $1.6 \%$, while the comparable estimates in mixed and substantially black areas were $1.2 \%$ and $.69 \%$, respectively. When data from all of the intersections were aggregated, the overall difference between the percentage of drivers observed (black and non-black) and those involved in traffic crashes (as victims) was also small and statistically insignificant.

The analyses presented herein have several limitations. First, the number of black traffic accident victims at some of the individual intersections was quite small (one or two not-at-fault drivers). This “small $n$ ” problem makes calculating statistical significance between field observation and traffic crash proportions impossible at the individual intersection level and is particularly problematic given that the greatest variation between observational and traffic crash data 
occurred at certain individual intersections. Second, data on what time of day the traffic crashes occurred were not available for this analysis. Thus, field observations made during daylight hours were compared against traffic crashes that occurred during the daytime and nighttime. We cannot rule out the possibility that comparing daytime observations to daytime crashes may have yielded different results. Finally, although made for sound methodological reasons, our decision to limit field observations of drivers to black or non-black leaves us unable to draw any conclusions either about the ethnic composition of the Miami-Dade County driving population, or about whether that population can be estimated using not-at-fault traffic crash data. As methods for observing drivers improve, we are hopeful that future researchers can more reliably capture information on ethnicity and test their findings against not-at-fault crash data.

Despite the limitations noted above, the main conclusion of this study is that not-at-fault drivers in two-vehicle crashes represent a reasonably accurate estimate of the racial composition of drivers on the road at a sample of high traffic intersections in unincorporated Miami-Dade County. Likewise, aggregating intersection-level traffic crash and observation data according to the racial composition of the areas in which intersections are located served to mitigate some of the error associated with measurement at individual intersections. This type of aggregation is preferred because of the possibility that traffic crashes may disproportionately occur in areas comprised predominantly of a single racial group. If, for example, a large number of accidents occur in predominantly black neighborhoods (perhaps because of poor road conditions), then a jurisdiction-wide estimate of the driving population based on the proportion of a group's involvement in crashes could be skewed and could possibly show a greater proportion of black drivers than actually exists. Aggregating traffic crash data according to the racial composition of neighborhoods (e.g., black, non-black, mixed) helps mitigate this problem. Specifically, researchers in a racial profiling study could compare the proportion of minorities stopped by the police to the proportion of minority traffic crash victims by individual neighborhood. Depending upon the traffic volume in the neighborhoods of interest, however, such an approach may not be feasible if the number of crashes involving minority drivers is small.

Further research is needed to replicate our findings and validate DPEM as a reliable estimate of the driving population in different cities and under different conditions. Our findings were based on a small number of high crash intersections that did not represent the driving population of Miami-Dade County as a whole. Nonetheless, our findings are consistent with quasi-induced exposure methods and add to the accumulating body of evidence on the usefulness of notat-fault crash data as a proxy for the driving population (Kirk \& Stamatiadis, 2001; Koornstra, 1973; Lyles, Stamatiadis, \& Lighthizer, 1991; Stamatiadis \& Deacon, 1997). Moreover, our findings are the first to validate quasi-induced exposure methods for estimating the racial composition of drivers under some conditions. 
Future researchers should continue to use driving population verification methods external to the crash data themselves to further test the validity of DPEM. High resolution traffic cameras offer an alternative, and potentially less costly, approach to field observation. In their analyses, researchers also should experiment with varying levels of aggregation. Differences between daytime, nighttime, and rush hour driving populations may be uncovered. Likewise, the racial composition of drivers on major roadways and thoroughfares may differ from that of drivers on backstreets or interstates within the same political subdivision. Using GIS software to overlay crashes and traffic stops should help future researchers examine the geographic correspondence between these events and should assist them in developing an analytical plan.

The implications of our findings for traffic studies generally, and racial profiling research specifically, are significant. In the normal course of investigating traffic crashes, law enforcement agencies that are not already doing so could easily record the race and ethnicity of the drivers involved in the crashes. ${ }^{3}$ If our findings in Miami-Dade County can be replicated, then these data will serve as a less costly and more comprehensive estimate of the driving population than traffic observation methods currently provide. Moreover, they will not be susceptible to the daytime bias inherent in observational data, and, unlike observation data, they can be aggregated or disaggregated in a variety of ways to help facilitate comparisons to police traffic stops. Just as importantly, officers investigating traffic crashes and capturing driver demographic data can provide more detailed and accurate information on race and ethnicity than can currently be gathered by traffic observers. Such data could be useful for assessing bias against minority groups-Hispanics, Native Americans, or Arabs, for example-for which observation data are highly suspect.

To be sure, not-at-fault crash data do not provide information on the racial composition of traffic violators. Currently, however, all but a few observation studies assume that drivers violate the plethora of traffic regulations proportionately to their racial group's representation in the driving population. Further evidence is clearly needed to either validate or invalidate this assumption. The collection of DPEM data should help further this endeavor by providing the benchmark against which to compare violator data. In addition to the traffic radar cameras mentioned previously, red light cameras are being used in an increasing number of cities. Researchers should explore the possibility of using photos from these devices as an objective indicator of violation rates among

\footnotetext{
${ }^{3}$ We do not know the proportion of law enforcement agencies that currently collect race and ethnicity data on drivers involved in traffic accidents. However, we are aware of several agencies that collect this information even though their state's uniform traffic accident report does not contain a data field for driver race. For these agencies, developing a mechanism for collecting accident victim race data was a relatively easy process.
} 
racial and ethnic groups. In addition, the racial composition of speeders identified by aerial radar may also prove a "color-blind" method for establishing violation rates among racial groups.

Future research should also explore whether at-fault drivers in two-vehicle crashes could be used as a proxy for the violating population. Traffic safety engineers estimate risk among subpopulations of drivers by dividing the at-fault proportions of these populations by their not-at-fault proportions (Carr, 1969). Ratios less than or equal to one, for any particular racial group, would suggest that the group was (1) not disproportionately causing crashes, and (2) not being disproportionately singled out by the police when attributing fault. Ratios greater than one would indicate that either one or both of the above statements was false and would consequently require further inquiry, perhaps by comparing the proportion of observed violators (by race) to their proportion of the at-fault drivers in police crash databases. If at-fault drivers can be established as a reasonable proxy for violators, then traffic observation methods can be eliminated entirely, saving considerable time and expense.

Until recently there has only been limited interest in estimates of the driving population by demographic characteristics. Actuarial statisticians working with insurance companies have shown the most interest in the data. Today, however, concerns over racially biased policing and police misconduct concerning discretionary traffic stops have created a need to determine who drives on the roads in our cities. DPEM is the first empirically based measure designed to be an efficient and effective tool, which, if replicated, could satisfy the needs of traffic safety engineers, actuarial statisticians, and researchers, who all require a valid benchmark of the driving public. 


\section{References}

Bean, F., \& Tienda, M. (1987). The Hispanic population in the United States. Berkeley: University of California Press.

Bureau of Justice Statistics. (2003). Assessing measurement techniques for identifying race, ethnicity, and gender: Observation-based data collection in airports and at immigration checkpoints. Washington, DC: Author.

California Highway Patrol. (2000). Public contact demographic data summary report to the governor. Sacramento, CA: Author.

Carr, B. R. (1969). A statistical analysis of rural Ontario traffic crashes using induced exposure data. Crash Analysis \& Prevention, 1, 343-357

Connecticut Division of Criminal Justice. (2000). Interim report of traffic stops statistics, January 2000 to June 2000. Hartford, CT: Author.

Denton, N., \& Massey, D. (1989). Racial identity among Carribean Hispanics: The effect of double minority status on racial segregation. American Sociological Review, 54, 790-808.

DeYoung, D. J., Peck, R. C., \& Helander, C. J. (1997). Estimating the exposure and fatal crash rates of suspended/revoked and unlicensed drivers in California. Crash Analysis and Prevention 29(1), 17-23.

Engel, R. S., \& Calnon, J. M. (2004). Comparing benchmarks methodologies for police-citizen contacts: Traffic stop data collection for the Pennsylvania State Police. Police Quarterly 7, 97 - 125.

Engel, R.S., Calnon, J. M., \& Bernard, T. J. (2002). Theory and racial profiling: Shortcomings and future directions in research. Justice Quarterly, 19(2), 249-273.

Farley, R. (1996). The new American reality. New York: Russell Sage Foundation Press.

Feest, J. (1968). Compliance with legal regulations: Observation of stop sign behavior. Law \& Society Review II, 447-461.

Fridell, L. (2004). By the numbers: A guide for analyzing race data from vehicle stops. Washington, DC: Police Executive Research Forum. 
Fridell, L., Lunney, R., Diamond, D., \& Kubu, B. (2001). Racially biased policing: A principled response. Washington, DC: Police Executive Research Forum.

Greenwald, H. P. (2001). Final report: Police vehicle stops in Sacramento, California. Los Angeles, CA: University of Southern California, School of Policy, Planning, and Development.

Haight, F. A. (1970). A crude framework for bypassing exposure. Journal of Safety Research, 2, 26-29.

Harris, D. (1999). The stories, the statistics and the law: Why driving while black matters. Minnesota Law Review, 84 (265), 1-45.

Itzigsohn, J. (1998). Pan-ethnic identity among Dominicans in the United States: A case study. Sociological Forum, 16, 56-73.

Kirk, A., \& Stamatiadis, N. (2001). Evaluation of the quasi-induced exposure: Final report. Lexington, KY: University of Kentucky, Department of Civil Engineering.

Koornstra, M. J. (1973). A model for estimation of collective exposure and proneness from crash data. Crash Analysis \& Prevention, 5, 157-173.

Lamberth, J. (1997). Report of John Lamberth, Ph.D. American Civil Liberties Union. [Online]. Retrieved from http://archive.aclu.org/court/lamberth.html.

Lamberth, J. (1994). Revised statistical analysis of the incidence of police stops and arrests of black drivers/travelers on the New Jersey Turnpike between exits or interchanges 1 and 3 from years 1988 through 1991. Retrieved from http://www.lamberthconsulting.com/research_articles.asp.

Langan, P. A., Greenfeld, L. A., Smith, S. K., Durose, M. R., \& Levin, D. J. (2001). Contacts between police and public: Findings from the 1999 national survey. Washington, DC: Department of Justice.

Lange, J. E., Blackman, K. O., Johnson, M. B. (2001). Speed violation survey of the New Jersey Turnpike: Final report. Calverton, MD: Public Services Research Institute.

Lyles, R. W., Stamatiadis, P., \& Lighthizer, D. R. (1991). Quasi-induced exposure revisited. Crash Analysis \& Prevention, 23, 275-285.

McKelvey, F., \& Stamatiadis, N. (1988). Final report: A study of the relationship between older drivers and highway safety in the state of Michigan. East Lansing, MI: College of Engineering, Michigan State University. 
McKelvie, S., \& Schamer, L. (1988). Effects of night, passenger, and sex on driver behavior at stop signs. The Journal of Social Psychology, 128, 685-690.

McMahon, J., Garner, J., Davis, R., \& Kraus, A. (2003). How to correctly collect and analyze racial profiling data: Your reputation depends on it. Washington, DC: Office of Community Oriented Policing Services.

Miller, J. (2000). Profiling populations available for stops and searches. (Police Research Series, Paper No. 131). London: Home Office.

Missouri Attorney General's Office. (2000). Annual report on Missouri traffic stops. Retrieved from http://www.ago.state.mo.us/racialprofiling/2000/ racialprofiling 2000. htm.

New York Attorney General's Office. (1999). The New York City Police Department's “stop \& frisk" practices. New York: Author.

Parker, K., MacDonald, J., Alpert, G., Smith, M., \& Piquero, A. (2004). A contextual study of racial profiling: Assessing the theoretical rationale for the study of racial profiling at the local level. American Behavioral Scientist 47, 943-962.

Petrocelli, M., Piquero, A., \& Smith, M. R. (2003). Conflict theory and racial profiling: An empirical analysis of police traffic stop data. Journal of Criminal Justice 31(1), 1-12.

Ross, H. L. (1961). Traffic law violation: A folk crime. Social Problems, 8, 231-239.

San Diego Police Department. (2000). Vehicle stop study: Mid-year report. San Diego, CA: Author.

San Jose Police Department. (1999). Vehicle stop demographic study. San Jose, CA: Author.

Smith, M. R., \& Alpert, G. P. (2002). Searching for direction: Courts, social science, and the adjudication of racial profiling claims. Justice Quarterly 19(4), 673-703.

Smith, M. R., \& Petrocelli, M. (2001). Racial profiling? A multivariate analysis of police traffic stop data. Police Quarterly 4(1), 4-27.

Stamatiadis, N. (2002). Personal communication. 
Stamatiadis, N., \& Deacon, J. A. (1997). Quasi-induced exposure: Methodology and insight. Crash Analysis and Prevention 29(1), 37-52.

Staplin, L., \& Lyles, R. R. (1991). Age differences in motion perception and specific driving maneuvers problems. Transportation Research Record, 1325, 23-33.

Stutts, J. C., \& Martell, C. (1991). Older driver population and crash involvement trends, 1974-1988. Crash Analysis \& Prevention, 24(4), 317-327.

Terry v. Obio, 392 U.S. 1 (1968).

Thomas, D. (2002). $1^{\text {st }}$ annual report: Denver Police Department contact card data analysis. Denver, CO: Denver Police Department.

Thorpe, J. T. (1967). Calculating relative involvement rates in crashes without determining exposure. Traffic Safety Research Review, 11, 3-8.

Washington State Patrol. (2001). Report to the legislature on routine traffic stop data. Olympia, WA: Author.

Zingraff, M. T., Mason, H. M., Smith, W. R., Tomaskovic-Devey, D., Warren, P., McMurray, H. L., \& Fenlon, C. R. (2000). Evaluating North Carolina State Highway Patrol data: Citations, warnings, and searches in 1998. Raleigh, NC: North Carolina State University, Center for Crime and Justice Research. 
